\title{
Education, income and cultural participation across Europe*
}

\author{
Educación, renta y participación cultural \\ en Europa
}

\author{
Maria J. Perez-Villadoniga \\ Sara Suarez-Fernandez \\ University of Oviedo
}

\begin{abstract}
In this paper, we analyze the determinants of cultural participation in four European countries, particularly focusing on education and income. Using data from the 2015 modules of the European Union Statistics on Income and Living Conditions (EU-SILC) for Spain, Italy, France and Germany, we estimate a Zero Inflated Ordered Probit (ZIOP) to model participation in two cultural activities: attendance to cinema and visits to sites of cultural interest. We find that the effect of education varies between cinema and cultural visits, being its marginal effect more relevant for the last. On the contrary, given a certain level of education, an increase in income will bring more people to the cinema.
\end{abstract}

Keywords: cultural participation, education, cinema, museums.

JEL classification: Z11.

\section{Resumen}

En este artículo se analizan los determinantes de la participación cultural en cuatro países europeos, prestando particular atención al papel de la educación y la renta. Utilizando datos del módulo de 2015 de la Encuesta Europea de Ingresos y Condiciones de vida (EU-SILC) para España, Italia, Francia y Alemania, se estima un modelo Probit Ordenado con Inflación de Ceros (ZIOP) para modelizar la participación en dos actividades culturales distintas: asistencia al cine y visitas a lugares de interés cultural. Nuestros resultados muestran que el efecto de la educación varía entre la participación en las dos actividades, siendo su efecto marginal más importante para las visitas a lugares de interés cultural. Por otro lado, dado un determinado nivel educativo, un aumento de la renta hace que los individuos acudan más al cine.

Palabras clave: participación cultural, educación, cine, museos.

Clasificación JEL: Z11.

\section{Introduction}

Since the work of Baumol and Bowen (1966), there is a great concern among economists and sociologists regarding the determinants of cultural participation. Identifying the characteristics of cultural consumers is crucial both for public

* This study received funding from the Government of Spain (project ECO2017-86402-C2-1-R). 
agencies, to inform on cultural policy decisions, and for cultural practitioners, to encourage cultural consumption. This is especially challenging in a context where cultural public spending has been reduced in many European countries, diversification of leisure activities has increased (Falk and Katz-Gerro, 2016) and where new technologies have altered the consumption of many cultural goods (Handke et al., 2017).

Previous empirical evidence has identified income as an important factor determining cultural demand. Obviously, people with higher economic resources can afford more cultural consumption ${ }^{1}$. In general, participation in the arts is greater among females (for example, Purhonen et al., 2011; Borgonovi, 2004; Willenkens and Lievens, 2014), especially in highbrow activities (Christin, 2012). Given that acquiring a taste for culture requires time, older individuals tend to participate more frequently, although the effect depends on the particular activity (Gray, 2003; Borgonovi, 2004). Additionally, the effect of labor market status, as a proxy for working time, is not clear. While working longer hours increases individuals' income, leading to greater demand, it may also reduce leisure time.

Among individuals' socioeconomic and demographic characteristics, education has been found to be the most important determinant of cultural participation (see Ateca-Amestoy and Prieto-Rodriguez, 2013; Seaman, 2005, among others). Higher levels of education are associated with higher levels of cultural capital which, in turn, lead to greater interest in culture. A higher taste for culture is likely to foster cultural consumption. Besides, education has an indirect effect on cultural demand through income, as more educated individuals tend to hold better paid jobs, increasing their ability to pay (Prieto-Rodriguez et al., 2005).

Moreover, the effect of education on cultural consumption is likely different according to the type of cultural good (Falk and Katz-Gerro, 2015; Suarez-Fernandez et al., 2019). In general, more educated individuals tend to have the necessary skills to appreciate and enjoy highbrow cultural activities, which typically involve interpreting more complex symbolic contents than lowbrow activities. In this sense, in an analysis of cultural participation in Spain, Suarez-Fernandez et al. (2019) find that the effect of education on cultural consumption is larger for highbrow than for more popular lowbrow activities. Also, they find a positive effect of income on participation that is larger for more popular activities. Interestingly, comparing the marginal effects of both variables, their results suggest that education is more important in determining cultural participation than income.

While these factors have been shown to be fundamental in shaping cultural participation, the relevance of each determinant may vary across countries. For instance, as Falk and Katz-Gerro (2016) acknowledge, the role played by education may be less important in those countries with a relatively highly educated population.

\footnotetext{
${ }^{1}$ We should note that income may have another effect that works in the opposite direction, as more income implies a higher opportunity cost of leisure leading to lower cultural participation (Throsby, 1994; Zieba, 2009).
} 
Cross-national comparisons are important in order to better understand differences and similarities in the influence of the different factors and cultural policies across countries. This will allow EU countries to better understand their own situation and learn from one another (O'Hagan, 2017). Still, international comparisons on cultural participation are still scarce and are often based on national level surveys that cannot be easily compared (Falk and Katz-Gerro, 2016). Previous analyses of cultural participation at the European level include Van Hek and Kraaykamp (2013), who analyze differences in cultural consumption of highbrow culture using data from the Eurobarometer 2007; Katz-Gerro and Lopez-Sintas (2013), who examine individuals' tastes for music in several European countries with Eurobarometer 2001 data; Sisto and Zanola (2010), who focus on cinema attendance; or Falk and KatzGerro (2016), who use the EU-SILC 2006 to analyze the characteristics of visitors to museums and historical sites in $24 \mathrm{EU}$ countries.

In this paper, we add to this literature by examining the determinants of cultural participation across several EU countries. In particular, we consider two different cultural activities: cinema attendance and visits to sites of cultural interest (monuments, museums, archaeological sites and galleries). This comparison will allow us to shed some light on the relative importance across countries of certain variables, especially education and income, on participation decisions in two kinds of activities: those that can be regarded as more popular culture, as is the case of cinema, and those that are considered high-brow forms of art, such as visits to museums and historical sites.

We use data provided by the 2015 module of the European Union Statistics on Income and Living Conditions (EU-SILC) and focus on four of largest continental European countries, Spain, Italy, France and Germany. On the one hand, Spain and Italy are culturally closer, while different from France and Germany. This allows to identify similarities and differences on the impact that variables of interest may have on participation depending on the characteristics of the population across Europe that might be helpful in the design of cultural policies. We estimate Zero Inflated Ordered Probit models (ZIOP), which are appropriate when there is a large proportion of individuals reporting of non-attendance. This model allows, first, classifying respondents into two groups: attendants and non-attendants. Second, those who do not attend are categorized either as non-participants (individuals who wouldn't attend in any case) or as potential participants (those who may have not attended, but could decide under different circumstances). Therefore, we will analyze both individuals' decision to participate in each of the two cultural activities and the frequency of such participation.

The article is structured as follows. In Section 2 we describe the database used and in Section 3 we present the empirical model. The main results of the article are developed in Section 5. Lastly, Section 6 concludes. 


\section{Data}

To carry out the empirical analysis, we use as database the European Union Statistics on Income and Living Conditions (EU-SILC) for Spain, France, Italy and Germany. It is a harmonized survey that is conducted yearly across EU countries and gathers data on sociodemographic features such as gender, age, education level, labor status, income or health conditions. The EU-SILC 2015 incorporates a module dealing with social participation with supplementary information on attendance to several cultural activities during the previous year. Possible answers are limited to three categories: zero attendance, between one and three times and more than three times in the previous 12 months. We focus on cinema attendance and visits to cultural sites, that include historical monuments, museums, art galleries or archaeological sites. Our final sample is composed of 27234, 21491, 36501 and 22580 individuals in Spain, France, Italy and Germany, respectively. A summary of the number of respondents belonging to each category for the two activities is provided in Table 1 .

Casual inspection of the data reveals the resemblance between France and Germany in terms of cultural participation. Cinema attendance and visits to cultural sites are pretty similar in terms of frequencies of participation, with the proportion of low attendance around 30 percent (between one and three visits during the last year) and 20 per cent for high attendance (more than three times) to cultural sites. On the other hand, Spain and Italy exhibit a similar behavior between them, although reported differences between cinema participation and cultural visits are higher than in the case of France and Germany: non-attendance to cultural sites is around 10 percent higher than cinema non-attendance. It is noteworthy to highlight that in Spain and Italy, about 55-60 per cent of the sample have not attended cinema during the previous year, a figure that rises up to more than two thirds of the sample in the case

\section{TABLE 1}

FREQUENCY OF PARTICIPATION

\begin{tabular}{|l|c|c|c|c|}
\hline & Zero & $\begin{array}{c}\text { Between 1 and 3 } \\
\text { times }\end{array}$ & $\begin{array}{c}\text { More than 3 } \\
\text { times }\end{array}$ & Total \\
\hline Cinema & \multicolumn{5}{|l|}{} \\
\hline Spain & $15,352(56.4 \%)$ & $6,572(24.1 \%)$ & $5,310(19.5 \%)$ & 27,234 \\
France & $9,837(45.8 \%)$ & $5,917(27.5 \%)$ & $5,737(26.7 \%)$ & 21,491 \\
Italy & $22,012(60.3 \%)$ & $8,420(23.1 \%)$ & $6,069(16.6 \%)$ & 36,501 \\
Germany & $12,192(54.0 \%)$ & $6,976(30.9 \%)$ & $3,412(15.1 \%)$ & 22,580 \\
\hline Cultural visits & $18,074(66.4 \%)$ & $5,021(18.4 \%)$ & $4,139(15.2 \%)$ & 27,234 \\
Spain & $10,465(48.7 \%)$ & $6,766(31.5 \%)$ & $4,260(19.8 \%)$ & 21,491 \\
France & $26,087(71.5 \%)$ & $6,864(18.8 \%)$ & $3,550(9.7 \%)$ & 36,501 \\
Italy & $10,370(45.9 \%)$ & $7,682(34.0 \%)$ & $4,528(20.1 \%)$ & 22,580 \\
\hline
\end{tabular}

SOURCE: European Union Statistics on Income and Living Conditions (EU-SILC) 2015. 
of cultural visits. All in all, there is an important proportion of non-attendees to each activity in the four countries which can be interpreted as a zero inflation problem.

The main descriptive statistics for the whole sample of respondents, composed of individuals over 17 years up to 81 years old, are presented in Table 2 .

TABLE 2

DESCRIPTIVE STATISTICS

\begin{tabular}{|c|c|c|c|c|c|c|c|c|}
\hline & \multicolumn{4}{|c|}{ Spain } & \multicolumn{4}{|c|}{ France } \\
\hline Variable & Mean & Std. dev. & Min & Max & Mean & Std. dev. & Min & Max \\
\hline Female & 0.52 & 0.50 & 0 & 1 & 0.52 & 0.50 & 0 & 0 \\
\hline Age & 50.44 & 18.24 & 17 & 81 & 50.29 & 18.42 & 17 & 17 \\
\hline Income & 30.87 & 21.62 & 0 & 275.43 & 44.82 & 31.57 & 0 & 0 \\
\hline Primary & 0.26 & 0.44 & 0 & 1 & 0.14 & 0.34 & 0 & 0 \\
\hline Secondary & 0.46 & 0.50 & 0 & 1 & 0.56 & 0.50 & 0 & 0 \\
\hline Tertiary & 0.27 & 0.44 & 0 & 1 & 0.30 & 0.46 & 0 & 0 \\
\hline Single & 0.30 & 0.46 & 0 & 1 & 0.34 & 0.47 & 0 & 0 \\
\hline Married & 0.55 & 0.50 & 0 & 1 & 0.50 & 0.50 & 0 & 0 \\
\hline Inmigrant & 0.09 & 0.29 & 0 & 1 & 0.11 & 0.31 & 0 & 0 \\
\hline Good health & 0.70 & 0.46 & 0 & 1 & 0.64 & 0.48 & 0 & 0 \\
\hline Studying & 0.10 & 0.30 & 0 & 1 & 0.08 & 0.28 & 0 & 0 \\
\hline Working & 0.43 & 0.49 & 0 & 1 & 0.47 & 0.50 & 0 & 0 \\
\hline Retired & 0.21 & 0.41 & 0 & 1 & 0.32 & 0.47 & 0 & 0 \\
\hline Unemployed & 0.13 & 0.34 & 0 & 1 & 0.05 & 0.21 & 0 & 0 \\
\hline \multirow[t]{2}{*}{ Observations } & \multicolumn{4}{|c|}{27,234} & \multicolumn{4}{|c|}{21,491} \\
\hline & \multicolumn{4}{|c|}{ Italy } & \multicolumn{4}{|c|}{ Germany } \\
\hline Variable & Mean & Std. dev. & Min & Max & Mean & Std. dev. & Min & Max \\
\hline Female & 0.52 & 0.50 & 0 & 1 & 0.52 & 0.50 & 0 & 1 \\
\hline Age & 51.52 & 17.98 & 17 & 81 & 51.68 & 15.29 & 15 & 67 \\
\hline Income & 36.65 & 26.84 & 0 & 688.78 & 39.51 & 28.29 & 0 & 639.22 \\
\hline Primary & 0.16 & 0.37 & 0 & 1 & 0.02 & 0.15 & 0 & 1 \\
\hline Secondary & 0.67 & 0.47 & 0 & 1 & 0.65 & 0.48 & 0 & 1 \\
\hline Tertiary & 0.17 & 0.37 & 0 & 1 & 0.33 & 0.47 & 0 & 1 \\
\hline Single & 0.29 & 0.45 & 0 & 1 & 0.24 & 0.43 & 0 & 1 \\
\hline Married & 0.57 & 0.50 & 0 & 1 & 0.59 & 0.49 & 0 & 1 \\
\hline Inmigrant & 0.08 & 0.27 & 0 & 1 & 0.10 & 0.29 & 0 & 1 \\
\hline Good health & 0.65 & 0.48 & 0 & 1 & 0.63 & 0.48 & 0 & 1 \\
\hline Studying & 0.07 & 0.26 & 0 & 1 & 0.08 & 0.28 & 0 & 1 \\
\hline Working & 0.44 & 0.50 & 0 & 1 & 0.49 & 0.50 & 0 & 1 \\
\hline Retired & 0.25 & 0.43 & 0 & 1 & 0.35 & 0.48 & 0 & 1 \\
\hline Unemployed & 0.08 & 0.26 & 0 & 1 & 0.03 & 0.17 & 0 & 1 \\
\hline Observations & \multicolumn{4}{|c|}{36,501} & \multicolumn{4}{|c|}{22,580} \\
\hline
\end{tabular}

SOURCE: European Union Statistics on Income and Living Conditions (EU-SILC), 2015. 


\section{Empirical model}

Empirically, we analyze cultural demand using a Zero Inflated Ordered Probit (ZIOP) model (Harris and Zhao 2007). The ZIOP model is an extension of the ordered probit to accommodate ordered dependent variables characterized by an excessive proportion of zero observations. Regarding cultural participation, individuals can be classified into (potential) participants (who attend a positive number of times or, eventually, zero) and non-participants. This allows us to categorize two types of sample zeros. On the one hand, people who would not participate in the cultural activity in any case, in other words certain non-participants. On the other hand, individuals who may have not attended, but could decide to do so if some circumstances were different, that is to say, potential participants. Since the two types of zeros are determined by different behaviors, they cannot be assumed to be originated by the same data generation process. In the case of potential participants and attendants, ZIOP models allow distinguishing different intensities of attendance, that is, low or high attendance.

Following the standard literature (see Seaman 2006), we analyze cultural demand of each country as a function of the individuals' sociodemographic features. To do so, we estimate the following two equations for Spain, France, Italy and Germany separately explaining both the probability of participation and the intensity of the attendance, once being an attendant:

$$
\begin{aligned}
& \text { Probability of Participation }{ }_{i j}=f\left(\operatorname{Dem}_{i j}, \mathrm{Ed}_{i j}, \operatorname{Inc}_{i j}, \operatorname{Lab}_{i j}, \mathrm{HC}_{i j}, \operatorname{Reg}_{i j}\right) \\
& \text { Frequency of Attendance }{ }_{i j}=f\left(\operatorname{Dem}_{i j}, \mathrm{Ed}_{i j}, \operatorname{Inc}_{i j}, \operatorname{Lab}_{i j}, \mathrm{HC}_{i j}, \operatorname{Reg}_{i j}\right)
\end{aligned}
$$

Where the dependent variable in Equation [1] Probability of Participation ${ }_{i j}$ is a non-observable dummy variable that will be endogenously defined by the model, classifying individuals either as (potential) participants or non-participants; and in Equation [2] Frequency of Attendance ${ }_{i j}$ is an ordinal variable which takes value zero when the individual declares not having attended to the activity $\mathrm{j}$ but the model categorized her as a potential participant, value 1 when she declares low attendance (between one and three times during the last year), and value 2 when she has high attended (more than three times).

The probability of participation (Equation 1) will split the sample into two groups that might be so different that will be associated to two different data generation processes. For (potential) participants, the intensity in their demands will be modeled by the Frequency of Attendance (Equation 2). Although it could be hypothesized that some of the explanatory variables may differentially affect probability and frequency of participation, we included the same explanatory variables in both equations. By doing so, we can analyze the hypothesis that variables related to preferences (age, gender, education, movie valuations, etc.) would potentially determine the probability of participation, whereas economic restrictions, such as income, would probably explain the frequency of participation (Fernandez-Blanco, 2009) 
Now we discuss the explanatory variables included in the specification. First, Dem $_{i j}$ is a vector of demographic characteristics which includes gender, age, marital status (a set of dummies indicating whether the individual is single or married, being other situations the reference group). Second, $\mathrm{Ed}_{i j}$, is a vector of two dummy variables for secondary and tertiary education, with primary education as the reference category; Inc $_{i j}$ are the earnings of each individual, in thousands Euro. $\mathrm{Lab}_{i j}$ is a set of dummies for different labor market situations: working part-time, working full-time, unemployed and student, leaving those retired and other situations as the reference. $\mathrm{HC}_{i j}$ is the self-declared health condition, which conveys declaring very good health, good health, and fair health, in contrast to poor and very poor health conditions. Reg $_{i j}$ is a set of regional dummies ${ }^{2}$ to account for geographic differences within countries.

\section{Results}

In this section, we discuss the determinants of the probability of participating in cinema and cultural visits (Equation 1) and the effect of each explanatory variable on the frequency of attendance (Equation 2).

Table 3 displays, on the one hand, the determinants of the probability of ever attending to the cinema (columns 1a, 1b, 1c, 1d) for Spain, France, Italy and Germany, respectively. Negative signs of Equation 1 are interpreted as reducing the likelihood of cinema participation, that is to say, increasing the likelihood of being a certain non-participant. On the other hand, Table 3 shows the intensity of cinema attendance (columns 2a, 2b, 2c, 2d). Positive signs in Equation 2 mean higher probability of going to the cinema often.

Compared to their male peers, females are more likely cinema participants in the four countries. In terms of the intensity of their attendance, females attend more often than males in France and Germany. Older people are more prone to go to the cinema in Spain and France, whereas youths go with more probability in Italy and Germany, but the intensity of the participation decreases with age across the four countries.

More educated individuals show both higher a probability of participation and higher frequency of attendance, an effect which increases with education level in Spain, France and Italy. In Germany we find that education increases the likelihood of cinema participation, but does not affect its frequency. The effect of income is as expected in the four countries, individuals with higher income show not only higher tendency to participate but also higher intensity of attendance, although in a decreasing rate.

\footnotetext{
${ }^{2}$ This variable is not available in the EUSILC-2015 for Germany.
} 
TABLE 3

ZERO-INFLATED ORDERED PROBIT ESTIMATION FOR CINEMA, 2015

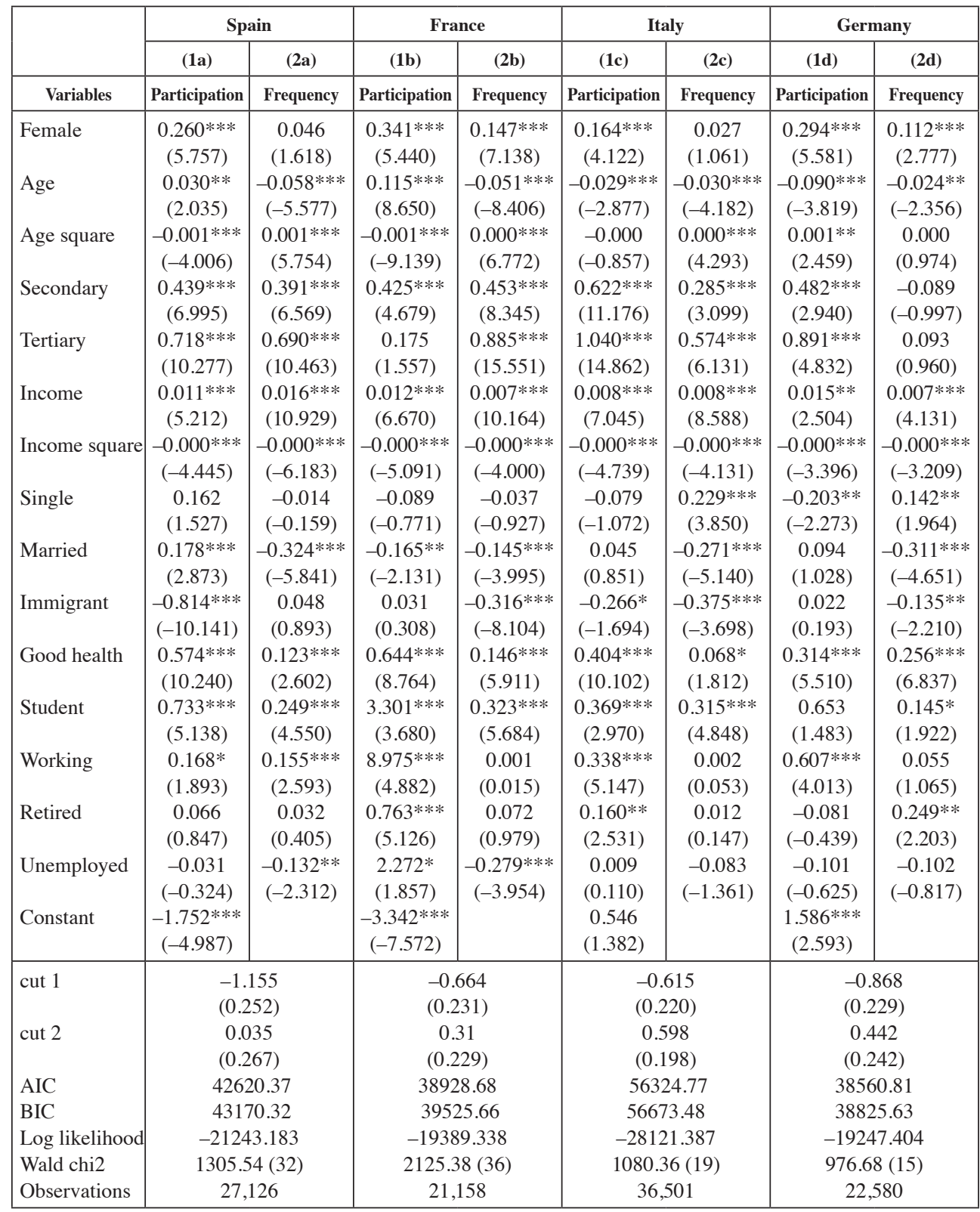

NOTE: Robust $z$-statistics in parentheses. $* * * p<0.01, * * p<0.05, * p<0.1$.

SOURCE: Own elaboration based on data from EU-SILC 2015. 
Regarding marital status, the effect is quite different across countries. In Spain, being married increases the chances of going to the cinema, but reduces its frequency. French respondents are less likely to participate and those who do so attend less often when married, compared to their widowed or separated peers. Being single increases the intensity of cinema attendance in Italy and Germany, whereas being married reduces it. Compared to those widowed or separated, German singles also show less chances of ever going to the cinema. In France, Italy and Germany, immigrants go less habitually to the cinema, and they are less likely participants in Italy and Spain. People declaring good health conditions are more likely cinema participants and also attend more often.

With regard to labor market status, students in the four countries exhibit both a higher probability and higher intensity of attendance, although less so in Germany. Being employed increases the likelihood of participating across countries, and also the intensity of the attendance in Spain. When retired, French and Italian people have more chances to attend, and Germans attend with higher frequency. Unemployment reduces the rate of cinema attendance in Spain and France.

Concerning cultural visits, Table 4 displays the determinants of the probability of participation (columns 1a, 1b, 1c, 1d) and the intensity of the attendance (columns 2a, 2b, 2c, 2d) in Spain, France, Italy and Germany, respectively.

Females go more frequently to museums, monuments, art galleries and archives than males in the four countries, and are also more prone to these visits in the case of Spain. In Spain, France and Italy, the likelihood of visiting cultural sites increases with age, although in a decreasing rate. In contrast, German youths go with increasingly more probability. The rate of cultural visits decreases with age in Spain and Italy, whereas it increases in France and Germany.

Spanish and Italian individuals are more likely to visit cultural sites and those who participate do it more frequently as their education increases. In Germany, higher levels of education are associated to a higher probability of attendance to museums and monuments compared to those who only achieved primary education. Regarding frequency of participation, Germans with tertiary education show a higher rate of attendance. The pattern differs in France, where although more educated individuals tend to visit cultural sites more frequently, the probability of attendance of those with tertiary education is significant lower relative to those with primary or secondary education. Higher earnings increase the intensity of the participation in cultural visits across the four countries, although in a decreasing rate. Italians with higher incomes are also more prone to do cultural visits.

In Spain and Italy, being married increases the likelihood of cultural visits compared to being widowed or separated, but reduces their regularity. Single Germans visit more often monuments and museums, whereas those who are married are less likely attendants. Good health conditions increase the chances and the intensity of cultural visits across the four countries. Cultural visits are less frequent among immigrants in France and Italy and, in Spain, their participation is less likely. 
TABLE 4

ZERO-INFLATED ORDERED PROBIT ESTIMATION FOR CULTURAL VISITS

\begin{tabular}{|c|c|c|c|c|c|c|c|c|}
\hline & \multicolumn{2}{|c|}{ Spain } & \multicolumn{2}{|c|}{ France } & \multicolumn{2}{|c|}{ Italy } & \multicolumn{2}{|c|}{ Germany } \\
\hline & (1a) & (2a) & (1b) & $(2 b)$ & (1c) & $(2 c)$ & (1d) & (2d) \\
\hline Variables & Participation & Frequency & Participation & Frequency & Participation & Frequency & Participation & Frequency \\
\hline Female & $\begin{array}{c}0.398 * * * \\
(4.529)\end{array}$ & $\begin{array}{c}0.140 * * * \\
(2.848)\end{array}$ & $\begin{array}{c}0.375 \\
(1.433)\end{array}$ & $\begin{array}{c}0.109 * * * \\
(6.315)\end{array}$ & $\begin{array}{c}0.048 \\
(0.683)\end{array}$ & $\begin{array}{c}0.122 * * * \\
(5.415)\end{array}$ & $\begin{array}{c}-0.044 \\
(-0.719)\end{array}$ & $\begin{array}{c}0.163 * * * \\
(7.477)\end{array}$ \\
\hline Age & $\begin{array}{l}0.150 * * \\
(2.361)\end{array}$ & $\begin{array}{c}-0.051 * * * \\
(-5.917)\end{array}$ & $\begin{array}{c}0.180 \text { *** } \\
(5.029)\end{array}$ & $\begin{array}{c}0.051 * * * \\
(13.741)\end{array}$ & $\begin{array}{c}0.047 * * \\
(2.355)\end{array}$ & $\begin{array}{c}-0.019 * * * \\
(-2.718)\end{array}$ & $\begin{array}{c}-0.165^{* * *} * \\
(-3.355)\end{array}$ & $\begin{array}{l}0.014^{*} \\
(1.702)\end{array}$ \\
\hline Age square & $\begin{array}{c}-0.002 * * \\
(-2.547)\end{array}$ & $\begin{array}{c}0.001 * * * \\
(6.347)\end{array}$ & $\begin{array}{c}-0.002^{* * *} \\
(-4.620)\end{array}$ & $\begin{array}{c}-0.000 * * * \\
(-11.678)\end{array}$ & $\begin{array}{c}-0.001 * * * \\
(-4.023)\end{array}$ & $\begin{array}{c}0.000 * * * \\
(4.191)\end{array}$ & $\begin{array}{c}0.002^{* * * *} \\
(3.657)\end{array}$ & $\begin{array}{c}0.000 \\
(0.354)\end{array}$ \\
\hline Secondary & $\begin{array}{c}0.640 * * * \\
(4.574)\end{array}$ & $\begin{array}{c}0.307 * * * \\
(3.927)\end{array}$ & $\begin{array}{c}0.911 \\
(1.117)\end{array}$ & $\begin{array}{c}0.593 * * * \\
(19.110)\end{array}$ & $\begin{array}{c}0.635^{* * * *} \\
(6.794)\end{array}$ & $\begin{array}{c}0.323 * * * \\
(3.332)\end{array}$ & $\begin{array}{c}0.966^{* * * *} \\
(3.820)\end{array}$ & $\begin{array}{c}-0.078 \\
(-0.722)\end{array}$ \\
\hline Tertiary & $\begin{array}{c}0.709 * * * \\
(3.947)\end{array}$ & $\begin{array}{c}0.776^{* * * *} \\
(8.079)\end{array}$ & $\begin{array}{c}-1.966^{* * *} \\
(-2.512)\end{array}$ & $\begin{array}{l}1.291 * * * \\
(33.133)\end{array}$ & $\begin{array}{c}1.108 * * * \\
(9.031)\end{array}$ & $\begin{array}{c}0.841 * * * \\
(7.781)\end{array}$ & $\begin{array}{c}1.378 * * * \\
(4.952)\end{array}$ & $\begin{array}{c}0.458 * * * \\
(3.827)\end{array}$ \\
\hline Income & $\begin{array}{c}-0.006 \\
(-1.027)\end{array}$ & $\begin{array}{c}0.017 * * * \\
(10.793)\end{array}$ & $\begin{array}{c}-0.000 \\
(-0.030)\end{array}$ & $\begin{array}{c}0.008 * * * \\
(13.129)\end{array}$ & $\begin{array}{c}0.010 * * * \\
(3.746)\end{array}$ & $\begin{array}{c}0.007 * * * \\
(5.413)\end{array}$ & $\begin{array}{c}0.034 \\
(1.643)\end{array}$ & $\begin{array}{c}0.005^{* * * *} \\
(7.947)\end{array}$ \\
\hline Income square & $\begin{array}{c}0.000 \\
(0.912)\end{array}$ & $\begin{array}{c}-0.000 \text { *** } \\
(-6.005)\end{array}$ & $\begin{array}{l}-0.000 * * \\
(-1.986)\end{array}$ & $\begin{array}{c}-0.000 * * * \\
(-3.994)\end{array}$ & $\begin{array}{c}-0.000 * * * \\
(-5.570)\end{array}$ & $\begin{array}{c}-0.000 * * * \\
(-2.772)\end{array}$ & $\begin{array}{c}0.000 \\
(0.540)\end{array}$ & $\begin{array}{c}-0.000 * * * \\
(-4.465)\end{array}$ \\
\hline Single & $\begin{array}{c}0.248 \\
(0.941)\end{array}$ & $\begin{array}{c}0.001 \\
(0.011)\end{array}$ & $\begin{array}{c}-0.299 \\
(-0.796)\end{array}$ & $\begin{array}{c}0.037 \\
(1.137)\end{array}$ & $\begin{array}{c}0.200 \\
(1.490)\end{array}$ & $\begin{array}{c}-0.012 \\
(-0.213)\end{array}$ & $\begin{array}{c}0.090 \\
(0.872)\end{array}$ & $\begin{array}{c}0.186^{* * * *} \\
(4.124)\end{array}$ \\
\hline Married & $\begin{array}{c}0.237 * * \\
(2.415)\end{array}$ & $\begin{array}{c}-0.186^{* * * *} \\
(-3.335)\end{array}$ & $\begin{array}{c}0.130 \\
(0.385)\end{array}$ & $\begin{array}{c}0.006 \\
(0.215)\end{array}$ & $\begin{array}{l}0.160 * * \\
(2.019)\end{array}$ & $\begin{array}{c}-0.126^{* *} \\
(-2.530)\end{array}$ & $\begin{array}{c}-0.244 * * \\
(-2.532)\end{array}$ & $\begin{array}{c}-0.016 \\
(-0.462)\end{array}$ \\
\hline Immigrant & $\begin{array}{c}-1.103 * * * \\
(-5.944)\end{array}$ & $\begin{array}{l}-0.185 \\
(-1.392)\end{array}$ & $\begin{array}{c}-0.388 \\
(-1.583)\end{array}$ & $\begin{array}{c}-0.194 * * * \\
(-6.120)\end{array}$ & $\begin{array}{c}0.319 \\
(1.239)\end{array}$ & $\begin{array}{c}-0.376 * * * \\
(-8.769)\end{array}$ & $\begin{array}{c}-0.029 \\
(-0.282)\end{array}$ & $\begin{array}{l}-0.033 \\
(-0.827)\end{array}$ \\
\hline Good health & $\begin{array}{c}0.680 * * * \\
(4.828)\end{array}$ & $\begin{array}{c}0.180 * * * \\
(3.191)\end{array}$ & $\begin{array}{c}2.308 * * * \\
(3.901)\end{array}$ & $\begin{array}{c}0.220 * * * \\
(10.953)\end{array}$ & $\begin{array}{c}0.509 * * * \\
(7.519)\end{array}$ & $\begin{array}{c}0.105^{* *} \\
(2.442)\end{array}$ & $\begin{array}{c}0.387 * * * \\
(5.816)\end{array}$ & $\begin{array}{l}0.288 * * * \\
(10.067)\end{array}$ \\
\hline Student & $\begin{array}{l}0.452 * \\
(1.665)\end{array}$ & $\begin{array}{c}0.357 * * * \\
(5.348)\end{array}$ & $\begin{array}{l}1.074 * * \\
(1.990)\end{array}$ & $\begin{array}{c}0.519 * * * \\
(9.834)\end{array}$ & $\begin{array}{c}0.513 \\
(1.221)\end{array}$ & $\begin{array}{c}0.520 * * * \\
(7.527)\end{array}$ & $\begin{array}{l}1.423^{*} \\
(1.893)\end{array}$ & $\begin{array}{c}0.136^{* * *} \\
(2.460)\end{array}$ \\
\hline Working & $\begin{array}{c}0.025 \\
(0.120)\end{array}$ & $\begin{array}{c}0.135^{* * *} * \\
(2.909)\end{array}$ & $\begin{array}{c}4.691 * * * \\
(8.160)\end{array}$ & $\begin{array}{c}-0.021 \\
(-0.509)\end{array}$ & $\begin{array}{c}0.340 * * \\
(1.972)\end{array}$ & $\begin{array}{c}0.079 \\
(1.209)\end{array}$ & $\begin{array}{c}0.491^{* * *} * \\
(3.998)\end{array}$ & $\begin{array}{l}-0.081 * \\
(-1.878)\end{array}$ \\
\hline Retired & $\begin{array}{l}0.183^{*} \\
(1.773)\end{array}$ & $\begin{array}{c}-0.011 \\
(-0.216)\end{array}$ & $\begin{array}{c}3.184 * * * \\
(4.579)\end{array}$ & $\begin{array}{c}0.178 * * * \\
(3.765)\end{array}$ & $\begin{array}{l}0.189 * \\
(1.933)\end{array}$ & $\begin{array}{c}0.052 \\
(0.886)\end{array}$ & $\begin{array}{c}0.106 \\
(0.836)\end{array}$ & $\begin{array}{c}-0.078 \\
(-1.385)\end{array}$ \\
\hline Unemployed & $\begin{array}{c}0.492 \\
(0.960)\end{array}$ & $\begin{array}{c}-0.235^{* * *} * \\
(-4.084)\end{array}$ & $\begin{array}{c}11.839 * * * \\
(13.812)\end{array}$ & $\begin{array}{c}-0.144 * * * \\
(-2.656)\end{array}$ & $\begin{array}{c}-0.437 \\
(-1.555)\end{array}$ & $\begin{array}{c}-0.027 \\
(-0.391)\end{array}$ & $\begin{array}{c}0.392 \\
(1.442)\end{array}$ & $\begin{array}{c}-0.392 * * * \\
(-4.059)\end{array}$ \\
\hline Constant & $\begin{array}{c}-3.777 * * * \\
(-3.767)\end{array}$ & & $\begin{array}{c}-3.787 * * * \\
(-4.150)\end{array}$ & & $\begin{array}{c}-1.035 \\
(-1.186) \\
\end{array}$ & & $\begin{array}{c}2.156 \\
(1.503)\end{array}$ & \\
\hline cut 1 & \multicolumn{2}{|c|}{$\begin{array}{c}0.461 \\
(0.498)\end{array}$} & \multicolumn{2}{|c|}{$\begin{array}{c}3.018 \\
(0.183)\end{array}$} & \multicolumn{2}{|c|}{$\begin{array}{c}0.962 \\
(0.213)\end{array}$} & \\
\hline cut 2 & \multicolumn{2}{|c|}{$\begin{array}{c}1.51 \\
(0.356)\end{array}$} & \multicolumn{2}{|c|}{$\begin{array}{c}4.063 \\
(0,184)\end{array}$} & \multicolumn{2}{|c|}{$\begin{array}{c}1.886 \\
(0.200)\end{array}$} & $\begin{array}{r}2.1 \\
(0.1\end{array}$ & $\begin{array}{l}45 \\
64)\end{array}$ \\
\hline AIC & \multicolumn{2}{|c|}{40831.72} & \multicolumn{2}{|c|}{39146.39} & \multicolumn{2}{|c|}{50387.06} & \multicolumn{2}{|c|}{43641.45} \\
\hline $\mathrm{BIC}$ & \multicolumn{2}{|c|}{41381.67} & \multicolumn{2}{|c|}{39743.37} & \multicolumn{2}{|c|}{50735.77} & \multicolumn{2}{|c|}{43906.27} \\
\hline Log likelihood & \multicolumn{2}{|c|}{-20348.859} & \multicolumn{2}{|c|}{-19498.196} & \multicolumn{2}{|c|}{-25152.532} & \multicolumn{2}{|c|}{-21787.724} \\
\hline Wald chi & \multicolumn{2}{|c|}{$1010.15(32)$} & \multicolumn{2}{|c|}{$3348.40(36)$} & \multicolumn{2}{|c|}{1061.20 (19) } & \multicolumn{2}{|c|}{$1295.59(15)$} \\
\hline Observations & \multicolumn{2}{|c|}{27,126} & \multicolumn{2}{|c|}{21,158} & \multicolumn{2}{|c|}{36,501} & \multicolumn{2}{|c|}{22,580} \\
\hline
\end{tabular}

NOTE: Robust $z$-statistics in parentheses. *** $p<0.01, * * p<0.05$, * $p<0.1$.

SOURCE: Own elaboration based on data from EU-SILC 2015. 
Cultural visits are more probable and frequent among students across the four countries, whereas unemployed people attend less often in Spain, France and Germany. Those retired show more chances of participating in cultural visits in Spain France and Italy, and their rate of attendance is also higher in France. Spanish workers have a higher intensity of attendance to monuments and museums, opposite to German workers. In France, Italy and Germany, to have a job increases the probability of participating.

We now turn to examine more deeply the effect of education and income in cultural participation across Spain, France Italy and Germany. On the one hand, in Table 5 we report the estimated marginal effects of education on the probability of being certain or recoverable non-attendant, or showing low or high attendance. These effects are computed considering primary education or lower as the reference category. We computed these effects at the observed values of the independent variables. On the other hand, Table 6 displays the estimated marginal effects of income on the different attendance categories. Reported coefficients respond to the effect of increasing income in 1000 euros.

Results show a strong similarity between Spain and Italy's behavior both in cinema and cultural visits. As education increases, the likelihood of being a certain non-attendant decreases sharply, especially when comparing primary with tertiary education levels. Among non-attendants, the probability of being a recoverable attendant in the two activities is negligible in both countries. Regarding frequency of attendance, the impact of having secondary education compared to those less educated is positive but moderate, whereas the effect of having tertiary education is high and especially intense for high attendance. Comparing cinema and cultural visits, the effect of education is clearly stronger for visiting museums, monuments, art galleries and archives.

TABLE 5

MARGINAL EFFECTS OF EDUCATION

\begin{tabular}{|c|c|c|c|c|c|c|c|c|}
\hline & \multicolumn{2}{|c|}{$\begin{array}{c}\text { Certain } \\
\text { non-attendant }\end{array}$} & \multicolumn{2}{|c|}{$\begin{array}{c}\text { Recoverable } \\
\text { non-attendant }\end{array}$} & \multicolumn{2}{|c|}{$\begin{array}{c}\text { Low } \\
\text { attendance }\end{array}$} & \multicolumn{2}{|c|}{$\begin{array}{c}\text { High } \\
\text { attendance }\end{array}$} \\
\hline & Secondary & Tertiary & Secondary & Tertiary & Secondary & Tertiary & Secondary & Tertiary \\
\hline \multicolumn{9}{|l|}{ Cinema } \\
\hline Spain & -0.1214 & -0.1924 & -0.0256 & -0.0622 & 0.0610 & 0.0829 & 0.0859 & 0.1717 \\
\hline France & -0.0558 & -0.0234 & -0.1092 & -0.2356 & 0.0537 & 0.0345 & 0.1113 & 0.2246 \\
\hline Italy & -0.1835 & -0.3019 & 0.0237 & 0.0043 & 0.0833 & 0.1284 & 0.0765 & 0.1693 \\
\hline Germany & -0.1385 & -0.2440 & 0.0730 & 0.0715 & 0.0575 & 0.1125 & 0.0081 & 0.0601 \\
\hline \multicolumn{9}{|c|}{ Cultural visits } \\
\hline Spain & -0.1515 & -0.2970 & 0.0157 & -0.0269 & 0.0673 & 0.1200 & 0.0684 & 0.2039 \\
\hline France & -0.0117 & 0.0687 & -0.2026 & -0.4746 & 0.1158 & 0.1238 & 0.0985 & 0.2820 \\
\hline Italy & -0.1618 & -0.2574 & 0.0413 & -0.0577 & 0.0748 & 0.1565 & 0.0457 & 0.1586 \\
\hline Germany & -0.2087 & -0.2713 & 0.1116 & -0.0300 & 0.0754 & 0.1214 & 0.0217 & 0.1799 \\
\hline
\end{tabular}

NOTE: Not significant (at the 5 percent level) marginal effects in italics.

SOURCE: Own elaboration based on data from EU-SILC 2015. 
In Germany, the higher the education level, the lower the probability of being a certain non-attendant, especially for cultural visits. The effect of education is also positive for recoverable non-attendants in the case of cinema participation. The effect of secondary education on attendance to the cinema and cultural visits is small but positive for low attendance, but it is not statistically significant for high attendance. Compared to Germans who only reached primary education, having tertiary education has a positive effect on participation which is stronger for cultural visits than for the cinema. Besides that, the effect of tertiary education in is larger for high attendance to monuments and museums than for low attendance. On the contrary, the effect is bigger for low than for high attendance to the cinema.

Cinema participation in France is more probable for individuals with secondary education compared to those with primary schooling. Surprisingly, the marginal effect of tertiary education on the probability of non-attendance is positive for visiting sites of cultural interest. French non-attendants to the cinema and cultural visits are very unlikely recoverable. Concerning positive attendance, as education increases so does the marginal effect on attendance to cinema and doing cultural visits. The positive effect of higher education levels on cinema participation is much larger for high than for low frequency of attendance. Despite the fact that more educated French people are more probably certain non-attendants, those who attend tend to exhibit the highest frequency of participation among all countries. Cultural visits are also more frequent for highly educated individuals but, while the effect of secondary and tertiary education on low attendance is similar, tertiary educated individuals are three times more likely to attend with high frequency to monuments and museums.

Finally, Table 6 shows the marginal effect of income on the four participation categories. Income has a clear positive impact on cultural participation, both in the cinema and cultural visits.

\section{TABLE 6}

MARGINAL EFFECTS OF INCOME

\begin{tabular}{|l|c|c|c|c|}
\hline & $\begin{array}{c}\text { Certain } \\
\text { non-attendant }\end{array}$ & $\begin{array}{c}\text { Recoverable } \\
\text { non-attendant }\end{array}$ & $\begin{array}{c}\text { Low } \\
\text { attendance }\end{array}$ & $\begin{array}{c}\text { High } \\
\text { attendance }\end{array}$ \\
\hline Cinema & -0.0020 & -0.0015 & 0.0008 & 0.0027 \\
\hline Spain & -0.0013 & -0.0012 & 0.0005 & 0.0020 \\
France & -0.0019 & -0.0005 & 0.0008 & 0.0016 \\
Italy & -0.0036 & 0.0003 & 0.0018 & 0.0015 \\
Germany & \multicolumn{5}{|l}{} \\
\hline Cultural visits & -0.0025 & -0.0007 & 0.0011 & 0.0021 \\
\hline Spain & 0.0000 & -0.0025 & 0.0007 & 0.0017 \\
France & -0.0019 & -0.0003 & 0.0012 & 0.0011 \\
Italy & -0.0079 & 0.0019 & 0.0034 & 0.0026 \\
\hline
\end{tabular}

NOTE: Not significant (at the 5 percent level) marginal effects in italics.

SOURCE: Own elaboration based on data from EU-SILC 2015. 
Among countries, there are differences between Germany, where the effect of income is much bigger for cultural visits than for the cinema, and Spain and France, where it's just slightly superior. Regarding non-attendance, people earning more income are less likely certain non-attendants, an effect slightly higher for cultural visits across the studied countries. Higher income increases the likelihood of being recoverable in Germany, opposite to the effect found in Spain, France and Italy, where the likelihood of the recoverability decreases. Regarding participation to the two activities, earning a higher salary increases more the probability of low attendance in Germany, whereas it increases more the chances of attending with higher frequency in Spain and France. In Italy, income increases equally the probability of low and high attendance to monuments and museums, while the effect is bigger for high attendance to the cinema.

\section{Conclusions}

In this paper we analyze the determinants of cultural demand in several EU countries, Spain, France, Italy and Germany. We focus on two different cultural activities: attendance to the cinema, which can be considered a popular (lowbrow) activity; and visits to sites of cultural interest (monuments, museums, archaeological sites and galleries), a highbrow cultural activity. Using data provided by the 2015 module of the European Union Statistics on Income and Living Conditions (EUSILC), we estimate Zero Inflated Ordered Probit models (ZIOP). This specification allows modelling the decision to participate and the intensity of participation simultaneously.

This adds to the literature dealing with cross-national comparisons on cultural participation. These analyses help us to understand the differences and similarities in the influence of different factors in shaping individuals' demand for culture, and may help in de design of cultural policies.

In the four countries analyzed, females are more likely to attend to the cinema, but conditional on participation, females attend to the cinema more often than males in France and Germany.

With respect to the decision to participate, higher levels of education are associated to a lower probability of never attending a cultural activity in Germany, Spain and Italy. In France, the probability of being a certain non-attendant increases with tertiary education in the case of visits to museums or cultural sites. However, French respondents exhibit relatively low rates of non-participation.

Among participants, we find that the higher the level of education the larger the increase in the probability of attendance, especially high attendance, in all four countries. Moreover, the effect of tertiary education on high attendance is significantly higher for cultural visits compared to the cinema. The marginal effects of education are remarkably large in the case of France. 
As expected, income also has a positive effect on participation, which is consistent with the fact that cultural goods are normal goods. A higher level of income reduces the likelihood of never participating in all countries. The marginal effect of income on high relative to low attendance is larger for highbrow activities in Spain and France, and the difference is larger for cinema. On the contrary, in the case of Germany the marginal effect of income is larger for highbrow activities

In sum, education is significantly more important than individuals' income in explaining cultural participation. Also, and in line with previous evidence (Falk and Katz-Gerro, 2016; Suarez-Fernandez et al., 2019), we find that the marginal effect of tertiary education on cultural participation is higher than the effect of secondary education, especially for visits to cultural sites. These results are consistent with the idea that cultural consumption involves the understanding of symbolic elements, especially in the case of highbrow culture, and more educated individuals are more likely to possess the necessary skills to appreciate highbrow cultural activities.

\section{Policy implications}

In sum, there are two main factors in hands of policy makers to promote cultural participation, income and education across European countries. However, we should be aware that by only reducing economic barriers, for example a tax reduction, we would not necessarily observe the desirable increase in attendance, especially in highbrow activities. To enhance cultural visits to monuments and museums, education seems to be the most effective tool. As a consequence, cultural policies should focus on the improvement of people's cultural capital through education policies to increase people's taste for the arts.

A main drawback of any policy aimed at the formation of artistic tastes is that its effects will only arise in the long term. In the past, policies of tastes' training were combined with cultural programs on radio and television. Nowadays, technological changes have eliminated the captive audiences of these media. Although supply is now much diverse, only those that are already interested in the arts demand these contents. Therein lies the importance of early and eventually compulsory education to develop artistic interests and tastes among the population.

\section{References}

Ateca-Amestoy, V., \& Prieto-Rodriguez, J. (2013). Forecasting accuracy of behavioural models for participation in the arts. Journal of Operational Research, 229, 124-131.

Baumol, W. J., \& Bowen, W. G. (1966). Performing arts-the economic dilemma: a study of problems common to theater, opera, music and dance. Twentieth Century Fund.

Borgonovi, F. (2004). Performing Arts: an economic approach. Applied Economics, 36 (17), 1871-1885. 
Christin, A. (2012). Gender and highbrow cultural participation in the United States. Poetics, 40 (5), 423-443.

Falk, M., \& Katz-Gerro, T. (2016) Cultural participation in Europe: Can we identify common determinants? Journal of Cultural Economics, 40, 127-162.

Fernandez-Blanco, V., Orea, L., \& Prieto-Rodriguez, J. (2009). Analyzing consumers heterogeneity and self-reported tastes: An approach consistent with the consumer's decision making process. Journal of Economic Psychology, 30 (4), 622-633.

Gray, C. (2003). Participation. In R. Towse (Ed.), A Handbook of Cultural Economics, Cheltenham: Edward Elgar, 356-365.

Handke, C.,Stepan,P., \& Towse, R.(2017). Cultural Economics, the Internet and Participation. In V. M. Ateca-Amestoy, V. Ginsburgh, I. Mazza, J. O’Hagan \& J. Prieto-Rodriguez (Eds.), Enhancing Participation in the Arts in the EU: Challenges and Methods, 295-310. Cham: Springer International Publishing.

Harris, M., \& Zhao, X. (2007). A zero-inflated ordered probit model, with an application to modelling tobacco consumption. Journal of Econometrics, 141, 1073-1099.

Katz-Gerro, T., \& Lopez-Sintas, J. (2013). The breadth of Europeans' musical tastes: Disentangling individual and country effects. Advances in Sociology Research, 14, 97-122.

O'Hagan, J. (2017). European Statistics on Participation in the Arts and Their International Comparability. In V. M. Ateca-Amestoy, V. Ginsburgh, I. Mazza, J. O’Hagan \& J. Prieto-Rodriguez (Eds.), Enhancing Participation in the Arts in the EU: Challenges and Methods, 3-17. Cham: Springer International Publishing.

Purhonen, S., Gronow, J., \& Rahkonen, K. (2011). Highbrow culture in Finland: Knowledge, taste and participation. Acta Sociologica, 54 (4), 385-402.

Seaman, B. A. (2005). Attendance and public participation in the performing arts: A review of the empirical literature. Nonprofit Studies Program, Georgia State University, Working Paper 05-03.

Seaman, B. A. (2006). Empirical studies of demand for the performing arts. In V. A. Ginsburg and D. Throsby (Eds.), Handbook on the Economics of Art and Culture, 1, 415-472. Amsterdam: Elsevier.

Sisto, A., \& Zanola, R. (2010). Cinema attendance in Europe. Applied Economics Letters, $17,515-517$.

Suarez-Fernandez, S., Prieto-Rodriguez, J., \& Perez-Villadoniga, M. J. (2019). The changing role of education as we move from popular to highbrow culture. Journal of Cultural Economics, 1-24.

Throsby, D. (1994). The Production and Consumption of the Arts: A View of Cultural Economics. Journal of Economic Literature, 32, 1-29.

Van Hek, M., \& Kraaykamp, G. (2013). Cultural consumption across countries: A multi-level analysis of social inequality in highbrow culture in Europe. Poetics, 41 (4), 323-341.

Zieba, M. (2009). Full-income and price elasticities of demand for German public theatre. Journal of Cultural Economics, 33, 85-108. 